\title{
Compulsory treatments in eating disorders: a systematic review and meta-analysis
}

\author{
Anna Rita Atti ${ }^{1}$ [D $\cdot$ Tomas Mastellari $^{1} \cdot$ Stefano Valente ${ }^{2} \cdot$ Maurizio Speciani $^{1} \cdot$ Fabio Panariello $^{2} \cdot$ Diana De Ronchi $^{1}$
}

Received: 6 August 2020 / Accepted: 24 September 2020 / Published online: 24 October 2020

(c) The Author(s) 2020

\begin{abstract}
Introduction The aims of this systematic review and meta-analysis are to provide a summary of the current literature concerning compulsory treatments in patients with eating disorders (ED) and to understand whether compulsorily and involuntarily treated patients differ in terms of baseline characteristics and treatment outcomes.

Methods Relevant articles were identified following the PRISMA guidelines by searching the following terms: "treatment refusal", "forced feeding", "compulsory/coercive/involuntary/forced treatment/admission", "eating disorders", "feeding and eating disorders", "anorexia nervosa", "bulimia nervosa". Research was restricted to articles concerning humans and published between 1975 and 2020 in English.

Results Out of 905 articles retrieved, nine were included for the analyses allowing the comparisons between 242 compulsorily and 738 voluntarily treated patients. Mean body mass index (BMI) was slightly lower in patients compelled to treatments. Mean illness duration, BMI at discharge and BMI variation showed no significant differences between the two groups. Average length of hospitalization was 3 weeks longer among compulsory-treated patients, but this did not result in a higher increase in BMI. No significant risk difference on mortality was estimated (three studies).

Conclusions Compulsory treatments are usually intended for patients having worse baseline conditions than voluntary ones. Those patients are unlikely to engage in treatments without being compelled but, after the treatments, albeit with longer hospitalisations, they do achieve similar outcomes. Therefore, we can conclude that forcing patients to treatment is a conceivable option.
\end{abstract}

Level of evidence Level I, systematic review and meta-analysis.

Keywords Compulsory admission $\cdot$ Involuntary treatment $\cdot$ Involuntary hospitalization $\cdot$ Eating disorders $\cdot$ Anorexia nervosa $\cdot$ Bulimia nervosa $\cdot$ BMI $\cdot$ Meta-analysis

\section{Introduction}

Eating disorders (ED) including among others, anorexia nervosa (AN) and bulimia nervosa (BN) are associated with severe morbidity and high mortality burden [1], have a serious impact on patient's quality of life, and are responsible for increased healthcare utilization and costs [2].

Outpatient care is recommended by clinical guidelines $[3,4]$ for most of the patients affected by ED [5], including

Anna Rita Atti

annarita.atti@unibo.it

1 Department of Biomedical and NeuroMotor Sciences, University of Bologna, Bologna, Italy

2 Department of Mental Health, Local Health Authority of Bologna, Bologna, Italy adolescents [6]; whereas for all persons with more severe clinical pictures, little or no differences between specialist inpatient care and active outpatient care (or a combination of both) have been demonstrated [7]. For patients with short illness duration and mild physical symptoms, primary treatment goals are restoring body weight and minimizing cognitive distortions. Conversely, according to a stage-matched intervention [8], in case of severe and enduring AN, treatment should be aimed to body weight stabilization, harm reduction, and improvements in psychosocial functioning $[9,10]$. Similarly, in patients affected by BN, to break the binge/purge cycle, an outpatients' setting is recommended, although hospitalization may occasionally be needed to force abstinence from binge/purge behaviors [11]. Besides symptoms severity [4], illness duration [12, 13], psychosocial functioning [14], and psychiatric comorbidities $[15,16]$ have 
been also claimed as relevant factors in the choice of the most appropriate treatment setting for both AN and BN [14] but, unfortunately, due to illness denial, engaging patients in out- or inpatients treatment can be challenging [17].

"Insight" in psychiatry encompasses the awareness of suffering from a mental illness, the understanding of the cause of such distress, and the acknowledgment of the need for treatment. Given these three assumptions, insight is necessarily a critical issue for patients' treatment $[18,19]$. For example, in studies carried out on patients affected by schizophrenia spectrum disorders, a clear relationship between low insight and poorer outcomes has been demonstrated [20, 21]; whereas for other psychiatric conditions, fewer data are available. To overcome the lack of insight, people affected by Severe Mental Illness (SMI) with impaired awareness of their health condition, when in need of care but refusing the therapies, might be legally committed to compulsory treatments. Persons affected by severe ED lack of a deeprooted awareness of their body size and might not recognize neither the severity of their psychopathological condition nor the health-related risks of extreme fasting and purging behaviors [22]. Therefore, even if controversial [23], compulsory treatments might occasionally be necessary [24] and justifiable [25] being usually compelled to administer lifesaving treatment [3, 26-29] and to prevent fatalities [30]. For example, in a large Danish sample of adult inpatients affected by AN, the use of involuntary measures was necessary in the $18 \%$ of cases [31]. The acceptance of an involuntary treatment, however, is debatable both from patients' as well as from professionals' side. Indeed, patients' rights and autonomy are juxtaposed with professionals' commitment to save lives and with their responsibility over patient's health [23]. Unfortunately, the lack of a common legislation on this topic among different countries and the absence of shared protocols between care providers (even within the same country) make this controversial issue even more difficult to be handled.

The literature on compulsory treatments in ED is mainly based on ethical, philosophical and legal principles rather than on empirical data [24] and, due to ethical reasons, randomised controlled trials aimed to compare voluntary and compulsory treatments are missing. Many literature reviews have been carried out under different perspectives [19, 20, 26-30] and overall, there is a large agreement on the need of further qualitative and quantitative research to fill this gap; conversely, under a clinical point of view, results are inconclusive.

Discrepancies in literature findings are principally due to differences in study population composition (age, gender, diagnoses, and illness duration) and in kind of treatment (feeding or artificial nutrition, out- or inpatients). Further sources of discrepancies are compulsory treatments' length (few days versus many weeks) and setting (psychiatric wards, general hospitals, residential homes) which depend on national legislations. Moreover, as the border between formal coercion and other forms of 'strong persuasion' in ED patients management is thin [33], treatments' comparison becomes even more difficult. A further source of ambiguity in estimating treatments' efficacy is related to the difficulties of defining appropriate outcomes: BMI restoration or binge-purging behaviors reduction, for example, is far from being appropriate outcomes to define an effective treatment. Efficacy should be alternatively evaluated based on psychopathology and functioning, which are also difficult to be quantitatively measured. The National Institute for Clinical Excellence (NICE) guidelines suggests that helping people to reach a healthy body weight for their age is a key goal which supports all the other psychological, physical and quality of life changes needed for improvement or recovery [3]. Unfortunately, as no agreement exists on the efficacy and usefulness of involuntary treatment for ED [23], in everyday clinical practice, professionals facing patients with severe ED stand alone in front of a difficult choice [35] being aware that compulsory hospitalizations demonstrated some benefits in the short term; whereas, in the long-term, have been proven to undermine the psychotherapeutic relationship and increase drop-out rates [34].

The aims of the present systematic review and metaanalysis are multiple. First, we sought to provide an update of the literature on this topic because a few studies $[31,36$, 37] have been published since the last two reviews published in 2014 [24, 38] were carried out. The second aim is to compare some of the features of patients voluntarily and compulsorily admitted identifying who is more likely to be compelled to treatments. Third, we were interested in estimating the extent to which voluntary and compulsory treatments yield different outcomes.

\section{Materials and methods}

\section{Search strategy}

Relevant articles were identified following the preferred reporting items for systematic reviews and meta-analyses (PRISMA) guidelines [39]. An extensive electronic database literature search was conducted in PubMed, PsycINFO, Scopus and Medline. These databases offer optimal coverage of relevant literature in the medical field (https://handbook-5-1. cochrane.org/chapter_6/6_searching_for_studies.htm).

The following terms were used: "treatment refusal", "forced feeding", "compulsory/coercive/involuntary/forced treatment/admission", "eating disorders", "feeding and eating disorders", "anorexia nervosa", "bulimia nervosa". Research was restricted to articles published in English and concerning humans between 1st January 1975 and 10th July 
2020. Additional articles were also found via hand searches of the reference lists of all retrieved articles.

\section{Selection procedure}

Two investigators (MS and TM) independently screened all relevant articles according to the following inclusion criteria: (1) presence of a study design based on a two-group comparison (compulsory versus voluntary); (2) presence of a description of socio-demographic and clinical characteristics of enrolled patients (age, gender, diagnosis, duration of illness and/or body mass index progression); and (3) presence of information on the hospitalization (length of stay, type). We excluded articles with different study design, reviews, case reports, commentaries and legal or ethical discussions. In case of disagreement on including or excluding articles between the two investigators, a senior author was involved for final decision (ARA).

\section{Quality evaluation}

The quality of included studies was assessed by the Newcastle Ottawa scale [40]. According to this scale, largely used for evaluating the value of non-randomized studies in metaanalyses, three factors need to be considered to score the quality of included studies. First, selection of the exposed and of the non-exposed cohort and ascertainment of exposure; second, comparability, assessed on the basis of study design and analysis, and whether any confounding variables were adjusted for; and third, the outcome which is evaluated on the basis of the follow-up period and cohort retention. The quality of the studies (good, fair and poor) is then rated by awarding stars in each domain: a "good" quality score requires 3 or 4 stars in selection, 1 or 2 stars in comparability, and 2 or 3 stars in outcomes; a "fair" quality score requires 2 stars in selection, 1 or 2 stars in comparability, and 2 or 3 stars in outcomes and, finally, a "poor" quality score reflects 0 or $1 \mathrm{star}(\mathrm{s})$ in selection, or 0 stars in comparability, or 0 or 1 star(s) in outcomes.

\section{Statistical analyses}

This meta-analysis was conducted on Review Manager 5.3 (Cochrane Collaboration software). Data are presented as mean differences or risk differences (RD), considering 95\% confidence intervals (CI). To provide a valid estimation of the pooled effect of included articles Random Effect models were used. Forest Plots were then created for graphical presentations of collected data. Based on the available information, the following outcomes were considered: length of stay, illness duration, BMI at admission, BMI at discharge, BMI variation, and mortality.
Heterogeneity, the variation in study outcomes between studies was tested by a Chi-square test and a $P$ value lower than 0.05 excluded the presence of statistically significant heterogeneity. The heterogeneity coefficient $I^{2}$ indicates that heterogeneity among studies. $I^{2}$ is null or might not be important when ranging between 0 and $40 \%$, moderate when ranging between 30 and $60 \%$, substantial when ranging between 50 and $90 \%$ and considerable when between 75 and $100 \%$ (https://handbook.cochrane.org/chapter_9/9_5_2_ identifying_and_measuring_heterogeneity.htm). Issue of heterogeneity in the present meta-analysis have been addressed by sensitivity analyses.

\section{Results}

Figure 1 illustrates in detail the procedure of articles' selection. Out of 905 articles retrieved, 405 duplicates were removed and 500 were left. After reading title and or abstract, 328 were further excluded and 172 were extensively examined. After reading the full text, 73 articles with a legal or ethical perspective, 41 reviews, 28 case reports, 20 commentaries, and one full text not available were eliminated leaving nine articles available for the systematic revision and the meta-analysis.

Table 1 reports a detailed description of the nine studies included in the quantitative analysis. Overall, $242 \mathrm{com}$ pulsory-treated patients are compared to 738 voluntary patients. The large majority are female. Mean age ranges between 16 and 37.6 years and illness duration between 1.9 and 18.3 years. All articles have a naturalistic retrospective study design and are carried out in Units specialized in the treatment of ED situated in the United Kingdom [37, 41-43], Australia [44-46], the United States [47] and Norway [36]. All studies but one [46] are embedded in a single clinical setting and enrolled patients over the years (between two and twelve years). Some of them collected information through medical record and national registry but only four studies [37, 41-43] reported data on mortality. Even if AN was the most common clinical diagnosis among patients treated compulsorily, there were also cases of treatments compelled to patients affected by $\mathrm{BN}$ or eating disorders not otherwise specified (EDNOS).

In Table 2, the occurrence of prior hospitalizations, the extent of psychiatric comorbidities as well as mortality rates are described. All studies but two [36, 43] reported information on prior hospitalizations that were more frequent in the compulsory group compared to the voluntary one. Apart from two studies [36, 43] which missed to report information about psychiatric comorbidities, in the remaining studies, the occurrence of depression, substance abuse and self-harm was higher in the compulsorythan in the voluntary-treated patients. Unfortunately, the 
Fig. 1 Flowchart representing the study selection procedure

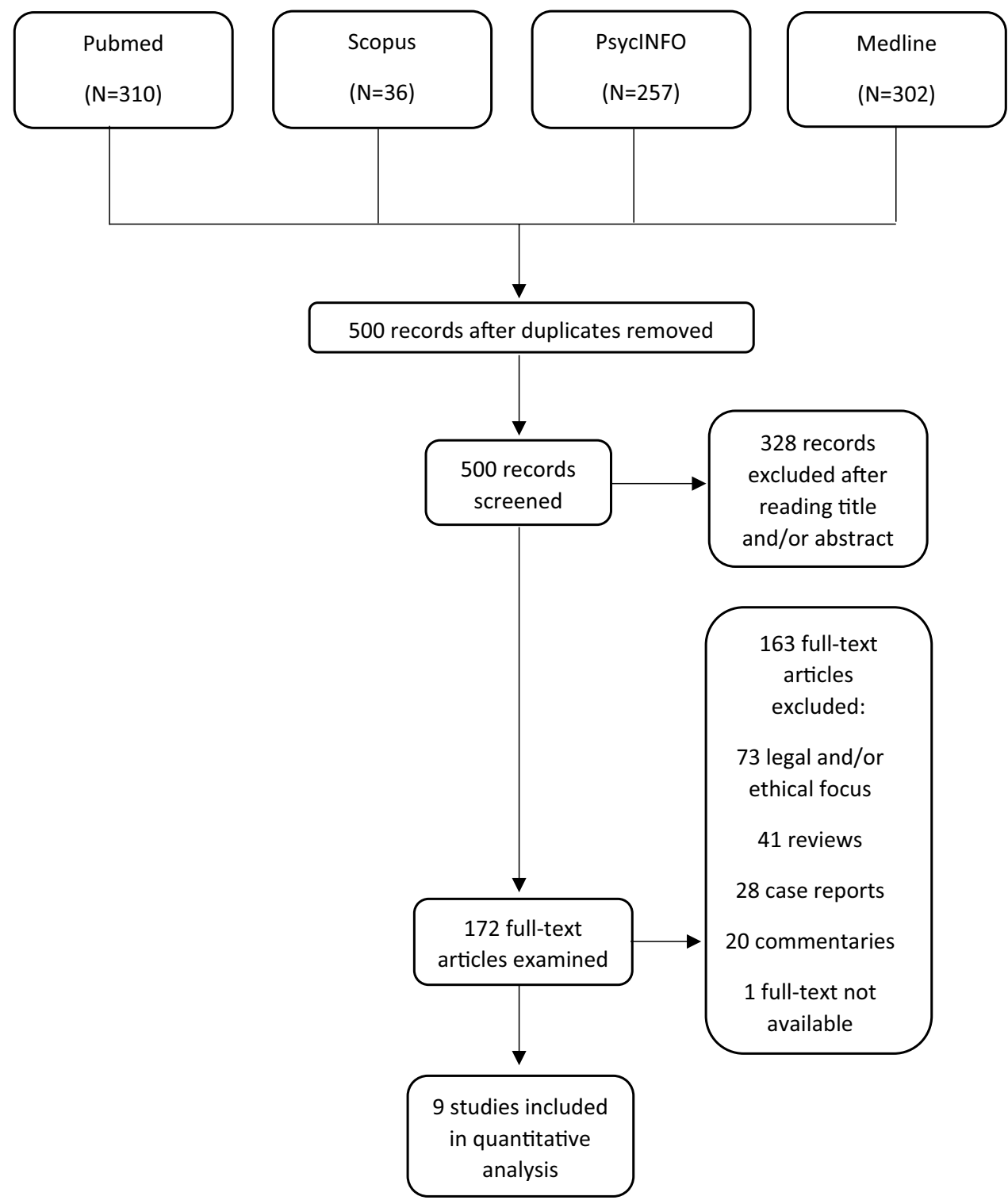

wide heterogeneity of the type of information provided about comorbidity precluded us the possibility of metaanalyzing the data.

\section{Illness duration}

Information on illness duration (before treatment) was reported in 5 articles. Illness duration was longer in the compulsorily treated groups in three articles [37, 43, 45], was shorter in another article [36] and was similar in the last one [47]. Overall, mean illness duration was not statistically significantly different between the compulsory and voluntary group (Fig. 2).

\section{BMI}

Data on mean BMI at admission were recorded in six articles. All studies but one [47] concerned patients with mean BMI equal or lower than $15 \mathrm{~kg} / \mathrm{m}^{2}$. The lowest mean BMI $\left(11.8 \pm 2.3 \mathrm{~kg} / \mathrm{m}^{2}\right)$ was reported in the compulsory group by Serfaty and colleagues in a small study published in 1998 [43]. Although only two studies [36, 45] reported a statistically significant difference in mean BMI at admission between groups, overall the compulsory-treated patients $(N=226)$ had a slightly lower mean BMI compared to the voluntary ones $(N=704)$ with an estimated mean difference equal to $0.57 \mathrm{~kg} / \mathrm{m}^{2}$ (confidence interval: -0.22 to -0.91 ) (Fig. 3). When only studies involving 


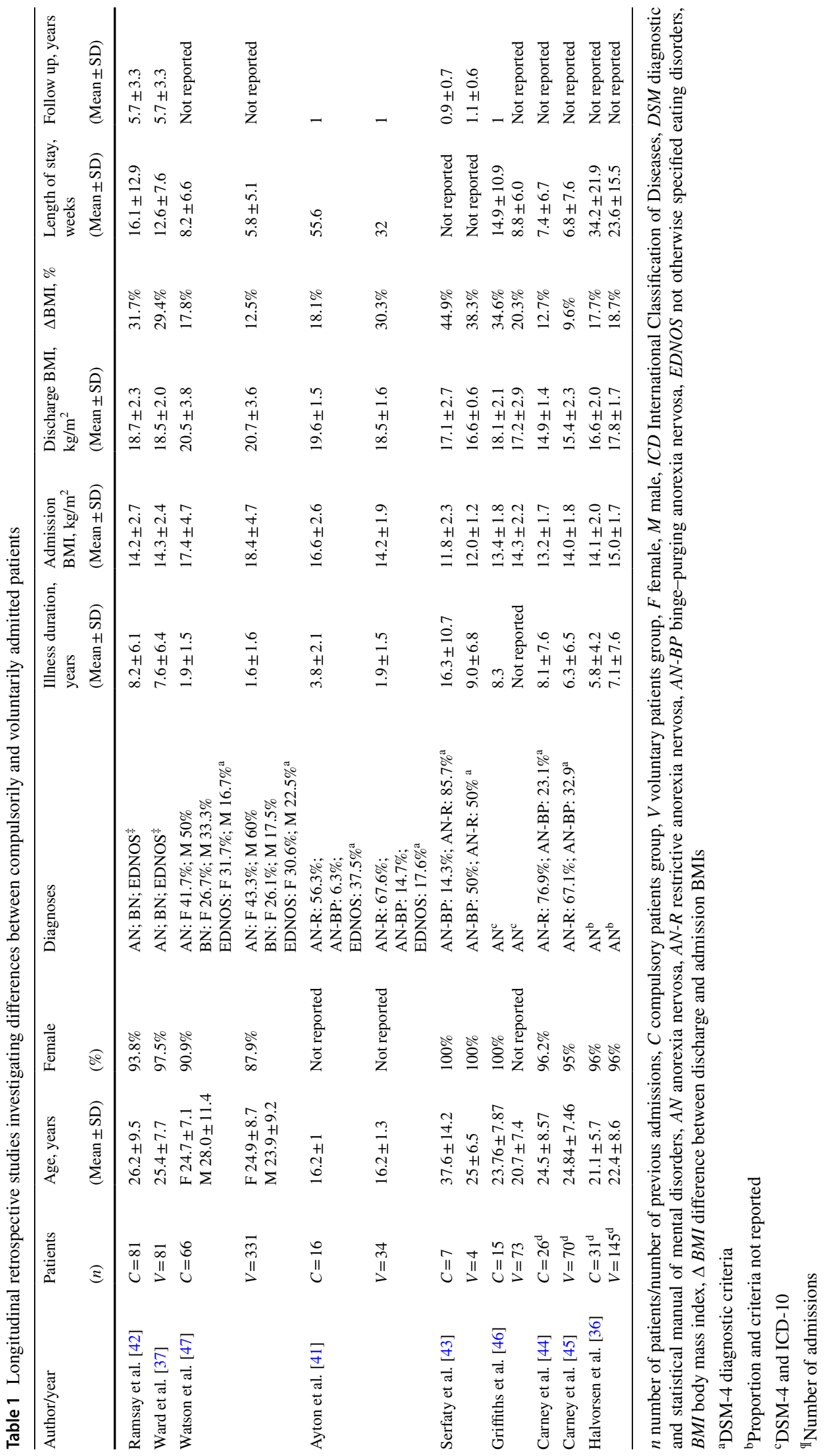


Table 2 Longitudinal retrospective studies investigating previous admissions, mortality and/or psychiatric comorbidities in compulsorily and voluntarily admitted patients

\begin{tabular}{|c|c|c|c|c|c|c|c|c|}
\hline \multirow[t]{2}{*}{ Author/year } & \multirow{2}{*}{$\begin{array}{l}\text { Patients } \\
(n)\end{array}$} & \multirow{2}{*}{$\begin{array}{l}\text { Previous admis- } \\
\text { sions } \\
(\text { mean } \pm \mathrm{SD}) \text { or } \\
(\%)\end{array}$} & \multirow{2}{*}{$\begin{array}{l}\text { Mortality } \\
(\%)\end{array}$} & \multirow{2}{*}{$\begin{array}{l}\text { Psychiatric comor- } \\
\text { bidities } \\
(\%)\end{array}$} & \multicolumn{4}{|c|}{ Study quality (Ottawa Score) } \\
\hline & & & & & Selection & Comparability & Outcome & Total \\
\hline Ramsay et al. [42] & $C=81$ & $3.3 \pm 3.2$ & 12.3 & Self-harm $59.3 \%$ & 4 & 2 & 2 & 8 \\
\hline Ward et al. [37] & $V=81$ & $1.8 \pm 2.2$ & 12.3 & Self-harm $33.3 \%$ & 3 & 2 & 3 & 8 \\
\hline \multirow[t]{2}{*}{ Watson et al. [47] } & $C=66$ & $3.0 \pm 7.4$ & - & $\begin{array}{l}\text { Depression } \\
45 \%(\mathrm{~F}) ; \\
66.7 \%(\mathrm{M}) \\
\text { Substance abuse } \\
30 \%(\mathrm{~F}) ; \\
16.7 \%(\mathrm{M})\end{array}$ & 3 & 1 & 1 & 6 \\
\hline & $V=331$ & $1.4 \pm 3.3$ & - & $\begin{array}{l}\text { Depression } \\
41.9 \%(\mathrm{~F}) ; \\
40 \%(\mathrm{M}) \\
\text { Substance abuse } \\
25.1 \%(\mathrm{~F}) ; \\
12.5 \%(\mathrm{M})\end{array}$ & & & & \\
\hline \multirow[t]{2}{*}{ Ayton et al. [41] } & $C=16$ & $87.5 \%$ of $C \geq 1$ & 0 & $\begin{array}{l}\text { Depression } 96.6 \% \text {; } \\
\text { OCD } 12.5 \% \\
\text { ASD } 18.6 \% \\
\text { Self-harm } 75 \%\end{array}$ & 3 & 2 & 1 & 6 \\
\hline & $V=34$ & $29.4 \%$ of $V \geq 1$ & 6.9 & $\begin{array}{l}\text { Depression } 58.8 \% \text {; } \\
\text { OCD } 14.7 ; \\
\text { ASD } 11.8 \% \\
\text { Self-harm } 11.8 \%\end{array}$ & & & & \\
\hline \multirow[t]{2}{*}{ Serfaty et al. [43] } & $C=7$ & - & 0 & - & 2 & 0 & 1 & 3 \\
\hline & $V=4$ & - & 0 & - & & & & \\
\hline \multirow[t]{2}{*}{ Griffiths et al. [46] } & $C=15$ & $\begin{array}{l}\text { Inpatients } 40 \% \text {; } \\
\text { Outpatients } 6.7 \% \text {; } \\
\text { Both } 40 \%\end{array}$ & - & $\begin{array}{l}\text { 60\% (affective } \\
\text { disorder 26.7\%; } \\
\text { OCD 6.7\%; } \\
\text { schizophrenia 6.7\%; } \\
\text { personality disorder } \\
20 \% \text {; } \\
\text { attempted } \\
\text { suicide 20\%; } \\
\text { substance abuse } \\
13.3 \% \text { ) }\end{array}$ & 4 & 1 & 1 & 6 \\
\hline & $V=73$ & $\begin{array}{l}\text { Inpatients } 42 \% \text {; } \\
\text { Outpatients } 40 \%\end{array}$ & - & - & & & & \\
\hline Carney et al. [44] & $C=26 \llbracket$ & 3.9 & - & $85 \%$ & 4 & 1 & 1 & 6 \\
\hline Carney et al. [45] & $V=70$ & 1.7 & & $70 \%$ & 4 & 1 & 3 & 8 \\
\hline $\begin{array}{l}\text { Halvorsen et al. } \\
\text { [36] }\end{array}$ & $\begin{array}{l}C=31 \\
V=145 \mathbb{I}\end{array}$ & & & & 3 & 2 & 3 & 8 \\
\hline
\end{tabular}

$n$ number of patients/number of previous admissions, $C$ compulsory patients group, $V$ voluntary patients group, $M$ males, $F$ females, $O C D$ obsessive compulsive disorder, $A S D$ autistic spectrum disorder

II Number of admissions

patients affected by AN were considered, results were confirmed with a mean BMI difference between the compulsory and the voluntary groups equal to $-0.84 \mathrm{~kg} / \mathrm{m}^{2}$ (confidence interval: -1.30 to -0.37 ) (data not shown).

No differences were detectable on BMI at discharge in the six articles reporting this information (Fig. 4). When only articles on patients affected by AN were considered, differences were similar and not statistically significant. Noticeably, regardless of type of treatment, in four [36, $43,45,46]$ out of six studies, BMI at discharge remained below $18.5 \mathrm{~kg} / \mathrm{m}^{2}$.

In all studies reporting both BMI at admission and at discharge, BMI variation was computed as the difference between post- and pre-treatment BMI. The overall estimated 
variation was in favor of the compulsory group that gained, on average, $0.38 \mathrm{~kg} / \mathrm{m}^{2}$ more than the voluntary group but such minimal difference was not statistically significant (confidence interval: -15.00 to +0.90 ) (Fig. 5). When only studies that enrolled patients with AN were considered, results were unchanged. Since BMI changes during treatment might be influenced by initial BMI, percentages of changes were also computed. On average, the compulsory-treated patients gained the between 12.9 and $36.4 \%$ of admission BMI; whereas, voluntary-treated patients gained between 10 and $38.3 \%$ but again such difference was not statistically significant (mean BMI difference $3.8 \%$; confidence interval: -0.52 to +7.02 ). Neither results were influenced by the inclusion of the studies including only patients affected by AN.

\section{Hospitalization}

Information on length of hospitalization were available in 5 articles [36, 37, 45-47]. Length of stay varied widely (range 5.8-34 weeks) being on average three weeks longer among compulsory-treated patients than among voluntary ones (Fig. 6).

\begin{tabular}{|c|c|c|c|c|c|c|c|c|c|c|c|c|}
\hline \multirow[b]{2}{*}{ Study or Subgroup } & \multicolumn{3}{|c|}{ Compulsory } & \multicolumn{3}{|c|}{ Voluntary } & \multicolumn{3}{|c|}{ Mean Difference } & \multirow{2}{*}{\multicolumn{3}{|c|}{$\begin{array}{c}\text { Mean Difference } \\
\text { IV, Random, } 95 \% \mathrm{Cl}\end{array}$}} \\
\hline & Mean & SD & Total & Mean & SD & Total & Weight & IV, Random, $95 \% \mathrm{Cl}$ & Year & & & \\
\hline Serfaty et al. & 16.3 & 10.7 & 7 & 9 & 6.8 & 4 & $0.7 \%$ & $7.30[-3.06,17.66]$ & 1998 & & & \\
\hline Watson et al. & 1.85 & 1.45 & 66 & 1.6 & 1.62 & 331 & $61.3 \%$ & $0.25[-0.14,0.64]$ & 2000 & & & \\
\hline Ward et al. & 8.2 & 6.1 & 81 & 7.6 & 6.4 & 81 & $15.8 \%$ & $0.60[-1.33,2.53]$ & 2015 & & & \\
\hline Halvorsen et al. & 5.8 & 4.2 & 31 & 7.1 & 7.6 & 145 & $15.8 \%$ & $-1.30[-3.23,0.63]$ & 2016 & & & \\
\hline Total $(95 \% \mathrm{Cl})$ & & & 211 & & & 631 & $100.0 \%$ & $0.21[-0.66,1.08]$ & & & & \\
\hline $\begin{array}{l}\text { Heterogeneity: Tau }{ }^{2} \\
\text { Test for overall effect }\end{array}$ & $\begin{array}{l}.28 ; \mathrm{C} \\
=0.46\end{array}$ & $\begin{array}{l}=5 \\
P=0\end{array}$ & $\begin{array}{l}30, \mathrm{df}= \\
63)\end{array}$ & $=4(P=$ & 26) & $=259$ & & & & $!$ & Compulsory Voluntary & 10 \\
\hline
\end{tabular}

Fig. 2 Illness duration. Mean difference is computed as duration in compulsory treatment minus duration in voluntary treatment; thus, negative mean differences suggest that the compulsory group has a longer mean illness duration than the voluntary one

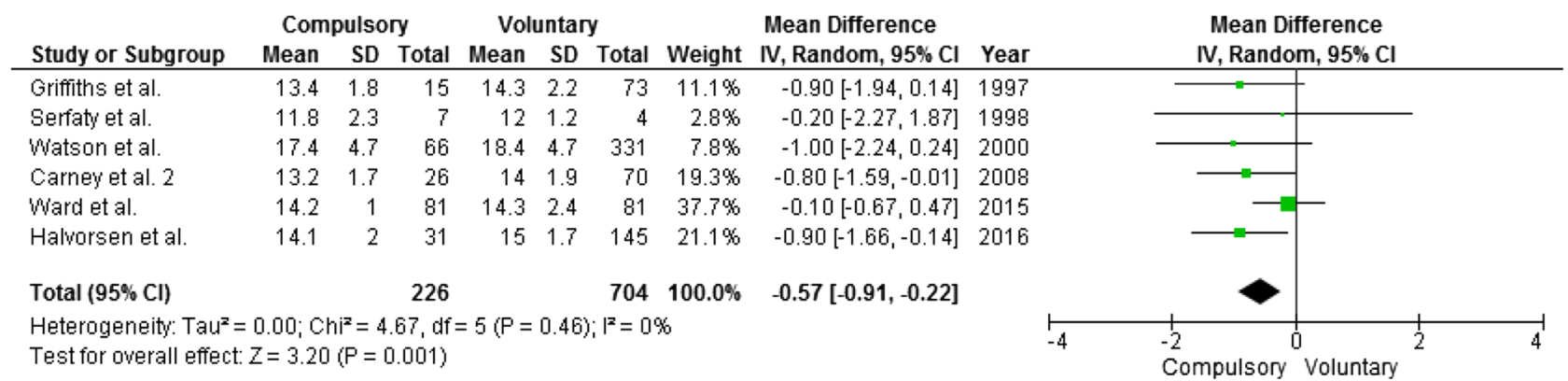

Fig. 3 BMI at admission. Mean difference is computed as BMI at admission in compulsory minus BMI at admission in voluntary; thus, negative mean differences suggest that the compulsory group has mean lower BMI than voluntary one

\begin{tabular}{|c|c|c|c|c|c|c|c|c|c|c|c|}
\hline \multirow[b]{2}{*}{ Study or Subgroup } & \multicolumn{3}{|c|}{ Compulsory } & \multicolumn{3}{|c|}{ Voluntary } & \multicolumn{3}{|c|}{ Mean Difference } & \multirow{2}{*}{$\begin{array}{c}\text { Mean Difference } \\
\text { IV, Random, } 95 \% \mathrm{Cl}\end{array}$} & \\
\hline & Mean & SD & Total & Mean & SD & Total & Weight & IV, Random, $95 \% \mathrm{Cl}$ & Year & & \\
\hline Griffiths et al. & 18.1 & 2.1 & 15 & 17.2 & 2.9 & 73 & $13.6 \%$ & $0.90[-0.35,2.15]$ & 1997 & & \\
\hline Serfaty et al. & 17.1 & 2.7 & 7 & 16.6 & 0.6 & 4 & $6.7 \%$ & $0.50[-1.58,2.58]$ & 1998 & & \\
\hline Carney et al. 2 & 14.9 & 1.4 & 26 & 15.4 & 2.3 & 70 & $21.4 \%$ & $-0.50[-1.26,0.26]$ & 2008 & & \\
\hline Ward et al. & 18.7 & 2.3 & 81 & 18.5 & 2 & 31 & $19.5 \%$ & $0.20[-0.66,1.06]$ & 2015 & & \\
\hline Halvorsen et al. & 16.6 & 2 & 31 & 17.8 & 1.7 & 145 & $21.5 \%$ & $-1.20[-1.96,-0.44]$ & 2016 & $\rightarrow-$ & \\
\hline Total $(95 \% \mathrm{Cl})$ & & & 226 & & & 654 & $100.0 \%$ & $-0.20[-0.81,0.40]$ & & & \\
\hline $\begin{array}{l}\text { Heterogeneity: Tau } \\
\text { Test for overall effec }\end{array}$ & $\begin{array}{l}0.30 ; 0 \\
z=0.6\end{array}$ & $=$ & $\begin{array}{l}1.09, d \\
0.51)\end{array}$ & $f=5(F$ & 0.0 & $i^{2}=$ & $55 \%$ & & & $\begin{array}{cccc}1 & 1 & & 1 \\
-4 & -2 & 0 & 2 \\
\text { Compuls ory } & \text { Voluntary }\end{array}$ & \\
\hline
\end{tabular}

Fig. 4 BMI at discharge. Mean difference is computed as BMI at discharge in the compulsory group minus BMI in the voluntary group; thus, negative mean differences suggest that the compulsory group has mean lower BMI than the voluntary one 


\section{Mortality}

The three studies [37, 41-43] reporting data on mortality were characterized by some degree of variability in follow-up length (range 0.9-5.7 years); however, no risk difference emerged between those treated compulsorily $(N=167)$ and voluntarily $(N=163)$ (Fig. 7$)$.

\section{Heterogeneity and sensitivity analyses}

Heterogeneity was not relevant $\left(I^{2}<40 \%\right)$ neither statistically significant $(p>0.05)$ in most of the analyses (details are reported below each Forest Plot). Regarding BMI at discharge (Fig. 4), heterogeneity was moderate $\left(I^{2}=55 \%\right)$ and approached statistical significance $(p=0.05)$. To overcome this limitation and provide a more exhaustive description of the available studies, we further implemented the sensitivity analyses described below.

All the previous analyses were additionally performed after the inclusion of the unique article that enrolled patients below legal age [41]. In this study, 16 compulsorily treated and 34 voluntarily treated adolescents with a restrictive $\mathrm{AN}$ and comorbid depression were followed up for one year. The inclusion in the meta-analyses of this

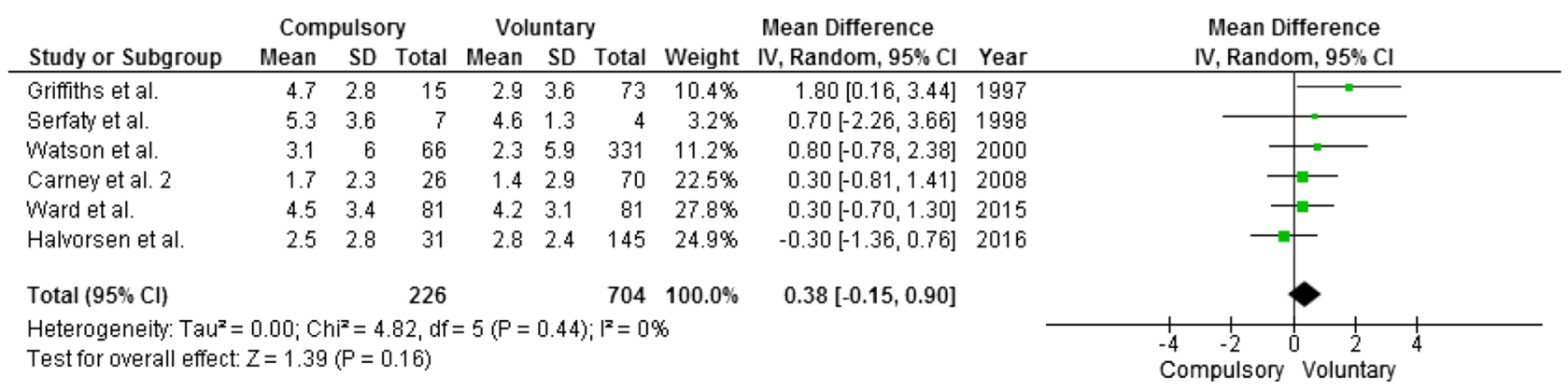

Fig. 5 BMI variance (post- minus pre-treatment BMI). Mean difference is computed as post-treatment BMI in the compulsory group minus post-treatment BMI in the voluntary group; thus, positive mean differences suggest that the compulsory group on average has a higher post-treatment BMI than the voluntary one

\begin{tabular}{|c|c|c|c|c|c|c|c|c|c|c|c|c|}
\hline \multirow[b]{2}{*}{ Study or Subgroup } & \multicolumn{3}{|c|}{ Compulsory } & \multicolumn{3}{|c|}{ Voluntary } & \multicolumn{3}{|c|}{ Mean Difference } & \multirow{2}{*}{\multicolumn{3}{|c|}{$\begin{array}{l}\text { Mean Difference } \\
\text { IV, Random, } 95 \% \mathrm{Cl}\end{array}$}} \\
\hline & Mean & SD & Total & Mean & SD & Total & Weight & IV, Random, $95 \% \mathrm{Cl}$ & Year & & & \\
\hline Griffiths et al. & 14.9 & 10.9 & 15 & 8.8 & 6 & 73 & $10.6 \%$ & $6.10[0.41,11.79]$ & 1997 & & & \\
\hline Watson et al. & 8.2 & 6.6 & 66 & 5.8 & 5.1 & 331 & $37.5 \%$ & $2.40[0.72,4.08]$ & 2000 & & & \\
\hline Ward et al. & 16.1 & 12.9 & 81 & 12.6 & 7.6 & 81 & $22.5 \%$ & $3.50[0.24,6.76]$ & 2015 & & & \\
\hline Halvorsen et al. & 34.2 & 21.9 & 31 & 23.6 & 15.5 & 145 & $5.9 \%$ & $10.60[2.49,18.71]$ & 2016 & & & \\
\hline Total $(95 \% \mathrm{Cl})$ & & & 219 & & & 700 & $100.0 \%$ & $3.10[1.01,5.19]$ & & & & \\
\hline \multicolumn{9}{|c|}{$\begin{array}{l}\text { Heterogeneity: } \text { Tau }^{2}=2.29 ; \mathrm{Ch}^{2}=7.10, \mathrm{df}=4(\mathrm{P}=0.13) ; \mathrm{I}^{2}=44 \% \\
\text { Test for overall effect: } Z=2.90(P=0.004)\end{array}$} & & $\frac{!}{-20}$ & Compulsory & Voluntary \\
\hline
\end{tabular}

Fig. 6 Length of hospitalization. Mean difference is computed as length of hospitalization in the compulsory group minus length of hospitalization in the voluntary group; thus, positive mean differences suggest that the compulsory group has on average a longer hospitalization than the voluntary one

\begin{tabular}{|c|c|c|c|c|c|c|c|c|c|c|}
\hline \multirow[b]{2}{*}{ Study or Subgroup } & \multicolumn{2}{|c|}{ Compulsory } & \multicolumn{2}{|c|}{ Voluntary } & \multicolumn{3}{|c|}{ Risk Difference } & \multirow{2}{*}{\multicolumn{3}{|c|}{$\begin{array}{c}\text { Risk Difference } \\
\text { M-H, Random, } 95 \% \mathrm{Cl}\end{array}$}} \\
\hline & Events & Total & Events & Total & Weight & M-H, Random, $95 \% \mathrm{Cl}$ & Year & & & \\
\hline Serfaty et al. & 0 & 7 & 0 & 4 & $7.4 \%$ & $0.00[-0.31,0.31]$ & 1998 & & & \\
\hline Ramsay et al. & 10 & 79 & 2 & 78 & $48.1 \%$ & $0.10[0.02,0.18]$ & 1999 & & & \\
\hline Ward et al. & 7 & 81 & 8 & 81 & $44.5 \%$ & $-0.01[-0.10,0.08]$ & 2015 & & & \\
\hline Total $(95 \% \mathrm{Cl})$ & & 167 & & 163 & $100.0 \%$ & $0.04[-0.05,0.13]$ & & & & \\
\hline Total events & 17 & & 10 & & & & & & & \\
\hline $\begin{array}{l}\text { Heterogeneity: Tau } \\
\text { Test for overall effect }\end{array}$ & $\begin{array}{l}0.00 ; \mathrm{Chi}^{2} \\
\mathrm{Z}=0.95(\mathrm{~F}\end{array}$ & $\begin{array}{l}=3.51 \\
=0.34\end{array}$ & $d f=2(P$ & $=0.17$ & $i^{2}=43 \%$ & & & $!_{-1}$ & $\begin{array}{ccc}1 & \\
-0.5 & 0.5 \\
\text { Compulsory Voluntary }\end{array}$ & +1 \\
\hline
\end{tabular}

Fig. 7 Mortality 
study did not changed the overall results. Since median illness duration was $7 \pm 6.3$ years, all the analyses were stratified accordingly: for studies with illness duration shorter than 7 years $[36,45,47]$ and for studies with illness duration equal or longer than 7 years [37, 43, 46], results were similar. Apart from one study [43] that did not report information on length of hospitalization, these data were available in the other eight studies [36, 37, 41, 42, 44-47]. As median length of hospitalization was 13.8 weeks, all the analyses were stratified accordingly. Results of studies with shorter [37, 44, 45, 47] and longer $[36,41,42,46]$ length of hospitalization were unchanged.

Applying the Newcastle Ottawa Scale, the quality of four $[36,37,42,45]$ studies was judged as very good (for details see Table 2). A sensitivity analysis run only with those studies demonstrated that BMI at admission was slightly lower in the 138 compulsory hospitalized patients compared to the 296 voluntary admissions with a mean difference equal to minus $0.62(-1.12$ to -0.12$)$. No differences were detectable between the two groups at the end of the treatment. Further additional analyses run only on studies which reported information on psychiatric comorbidity in both the voluntarily and the compulsorily treated groups gave similar results.

\section{Discussion}

The present systematic review of the literature and metaanalysis confirm the paucity of studies on compulsory treatments in ED and highlight the need of further research in this neglect area. The nine articles used for the present quantitative synthesis have a naturalistic study design and are mainly based on retrospective data collection; nevertheless, they provide a body of evidences on 242 patients affected by ED treated against their will. Findings of our meta-analysis can be summarized as follows:

(i) Compulsory treatments are compelled to patients with different clinical diagnoses, illness duration, and psychiatric comorbidity.

(ii) BMI after treatments is similar in the compulsory and in the voluntary groups. Sometimes treatments' end occurs when body weight is not yet fully restored.

(iii) Even if average length of hospitalization is three weeks longer among compulsory-treated patients, this does not result in a superior increase in BMI.

(iv) No significant Risk Difference on mortality exists between voluntarily and compulsorily treated patients (three studies available).

Since starvation can be a life-threating condition, compulsory treatments are forecast to be more likely in patients with lower BMI. Findings from our meta-analysis confirmed that overall BMI was statistically significant lower in the compulsory group, but the difference $\left(0.57 \mathrm{~kg} / \mathrm{m}^{2}\right)$ was not clinically relevant. There is a general agreement upon the fact that BMI is far from being a satisfactory measure of illness severity, but, unfortunately, the current available literature did not provide alternative information as only three $[41,46,47]$ studies reported different psychopathological measures that anyway were not comparable. Illness duration is assumed to be a further possible markers of illness severity. Indeed, illness duration was 1.7 years longer in the compulsory-treated group, but such difference was not statistically significant. Since the co-occurrence of depression, substance abuse and self-harm with ED could overturn the balance in favors of choosing a compulsory treatment, we focused our attention also on psychiatric comorbidity but the studies providing such information were few and too heterogeneous for a meta-analysis.

BMI at discharge and BMI difference after treatment between the compulsory and the voluntary groups were similar regardless of baseline BMI in all ED patients as well as in AN patient. Although BMI is not the most satisfactory measure to judge treatment efficacy in $\operatorname{ED}[48,49]$, such result demonstrates that compulsory treatments are neither superior nor inferior to voluntary ones in influencing weight gain. It is noteworthy that in some studies, BMI at discharge did not exceed 18.5 which is the WHO threshold identifying underweight [50]. According to a clinical perspective, this suggests that compulsory treatments per se are meaningful and need to be integrated in a long-lasting treatment program. Interestingly, the average length of hospitalization for compulsory-treated patients was longer (and presumably related costs were higher) without having a significant impact on BMI changes.

The main unresolved issue in judging the effectiveness of compulsory treatment in ED patients is that we do not know what would have happened to the patients who underwent compulsory treatment if they had not been compelled to such treatment. Unfortunately, this precludes the possibility of drawing any definitive conclusions; however, as the outcomes between compulsory and voluntary-treated patients did not differ, we can assume that there are no beneficial neither detrimental effects in the two types of treatment. Since patients who have been compelled to treatment appeared generally worse at baseline than the voluntary group, and given that they are highly unlikely to engage in treatment without being compelled to do so, whilst they achieve similar outcomes, albeit with longer length of stays, we can conclude that obliging the patients to the treatment does not undermine the effectiveness of the treatment itself and not forcing them does not reduce the probability of a favorable outcome. 
Furthermore, when patients compulsorily and voluntarily treated were compared, mortality was neither inferior nor superior. It is well acknowledged that AN has the highest mortality rate of any psychiatric illness and that mortality risks factors include illness chronicity, critically low body weight, and bingeing and purging behaviors. Given the delusional beliefs concerning patients' body image and the impaired cognitive performance caused by starvation, an accurate evaluation of individual's risk is mandatory and every effort of treating life-threatening cases must be implemented [25].

Unfortunately, all the publications on patient's (and family's) perspective on this topic have a qualitative design that prevented the possibility to include those study in this meta-analysis. Conversely, addressing patient's point of view would have been relevant: for example, patients reported that a trusting relationship with health professionals could even prevent the admission to be perceived as coercive [51]; furthermore, the degree of satisfaction after discharge was similar between voluntary and involuntary admissions [52]. Guarda et al. [53] found that nearly half of the patients who denied the need for treatment acknowledged it in just two weeks of inpatient care. In addition, Tan et al. [51] reported that while there were some differences in patients' and parents' perception of what constitutes capacity to choose for their own health, they all agreed that it would not be right to allow someone to die as a result of respecting their refusal of treatment.

Some limitations of the present meta-analysis deserve a comment. It should be noted that compulsory treatments are not an alternative form of therapy but rather a choice of care responding to different conditions: lack of insight, lack of compliance to therapy, psychopathological and medical severity. Therefore, every comparison between compulsory and involuntary treatments should be considered cautiously. As predictable, psychiatric comorbidities were more frequent in compulsory-treated patients, who also had a slightly lower BMI. Unfortunately, the small number of studies included in the meta-analysis and the reduced sample size of most of them prevented us from the possibility of running moderator analyses. Given the non-randomized nature of the studies included in this meta-analysis, pre-treatment differences between groups are the most relevant limitations to compulsory versus voluntary treatment comparisons. However, we used percentage of BMI changes to reduce the bias related to different baseline conditions.

To conclude, the available literature does not offer to the clinicians' useful information for compelling compulsory treatment or not and for predicting who will get benefits and who will not. However, as full recovery is possible even in severe ED cases, compulsory treatments should not be prohibited and might be justifiable and necessary [25]. As already happening for other psychiatric disorders, the preventive setting up of a joint crisis plan in which patient's treatment preferences for any future emergency are shared with the clinicians could be a collaborative strategy that further improves the therapeutic relationship [54]. To reduce patient's perception of coercion, the implementation of an outpatient- rather than an inpatientcompulsory treatment could be helpful. Similarly, the type of ward (a nutritional or internal medicine ward rather than a psychiatric locked ward) in which the compulsory treatment takes place could be relevant to improve patients' acceptability and fight stigma.

\section{What is already known on this subject?}

Compulsory treatments might be life-saving and can provide some benefits in the short term; whereas, in the long term, could undermine the therapeutic relationship.

\section{What this study adds?}

This study updates the literature on a neglected area of research suggesting that forcing ED patients to treatment is a conceivable option.

Funding Open access funding provided by Alma Mater Studiorum Università di Bologna within the CRUI-CARE Agreement. The authors received no specific funding for this work.

\section{Compliance with ethical standards}

Conflict of interest All authors declare having no conflict of interest. The declaration of Helsinki-Ethical principles for medical research involving humans-was followed.

Ethical approval Not applicable, not needed.

Informed consent Not applicable, not needed.

Open Access This article is licensed under a Creative Commons Attribution 4.0 International License, which permits use, sharing, adaptation, distribution and reproduction in any medium or format, as long as you give appropriate credit to the original author(s) and the source, provide a link to the Creative Commons licence, and indicate if changes were made. The images or other third party material in this article are included in the article's Creative Commons licence, unless indicated otherwise in a credit line to the material. If material is not included in the article's Creative Commons licence and your intended use is not permitted by statutory regulation or exceeds the permitted use, you will need to obtain permission directly from the copyright holder. To view a copy of this licence, visit http://creativecommons.org/licenses/by/4.0/.

\section{References}

1. Demmler JC, Brophy ST, Marchant A et al (2019) Shining the light on eating disorders, incidence, prognosis and profiling of patients in primary and secondary care: national data linkage 
study. Br J Psychiatry 216:105-112. https://doi.org/10.1192/ bjp. 2019.153

2. Ágh T, Kovács G, Supina D et al (2016) A systematic review of the health-related quality of life and economic burdens of anorexia nervosa, bulimia nervosa, and binge eating disorder. Eat Weight Disord 21:353-364. https://doi.org/10.1007/s4051 9-016-0264-x

3. NICE guideline (2017) Eating disorders: recognition and treatment. https://www.nice.org.uk/guidance/ng69. Accessed 1 Mar 2019

4. Yager J et al (2006) Treatment of patients with eating disorders, Third Edition. In: APA practice guidelines for the treatment of psychiatric disorders: comprehensive guidelines and guideline watches, 1st ed. American Psychiatric Association, Arlington, VA

5. Durham ML, La Fond JQ (1996) Assessing psychiatric care settings. Hospitalization versus outpatient care. Int J Technol Assess Health Care 12:618-633. https://doi.org/10.1017/s0266 462300010928

6. Gowers S., Clark A., C R, et al (2010) A randomised controlled multicentre trial of treatments for adolescent anorexia nervosa including assessment of cost-effectiveness and patient acceptability-the TOuCAN trial. Health Technology Assessment 14. https://doi.org/10.3310/hta14150

7. Hay PJ, Touyz S, Claudino AM et al (2019) Inpatient versus outpatient care, partial hospitalisation and waiting list for people with eating disorders. Cochrane Database Syst Rev 1:CD010827. https://doi.org/10.1002/14651858.CD010827. pub2

8. Treasure J, Stein D, Maguire S (2015) Has the time come for a staging model to map the course of eating disorders from high risk to severe enduring illness? An examination of the evidence. Early Interv Psychiatry 9:173-184. https://doi.org/10.1111/eip.12170

9. Hay P, Touyz S (2015) Treatment of patients with severe and enduring eating disorders. Curr Opin Psychiatry 28:473-477. https://doi.org/10.1097/YCO.0000000000000191

10. Wonderlich S, Mitchell JE, Crosby RD et al (2012) Minimizing and treating chronicity in the eating disorders: a clinical overview. Int J Eat Disord 45:467-475. https://doi.org/10.1002/eat.20978

11. Castillo M, Weiselberg E (2017) Bulimia nervosa/purging disorder. Curr Prob Pediatr Adolesc Health Care 47:85-94. https ://doi.org/10.1016/j.cppeds.2017.02.004

12. Hay PJ, Touyz S, Sud R (2012) Treatment for severe and enduring anorexia nervosa: a review. Aust N Z J Psychiatry 46:11361144. https://doi.org/10.1177/0004867412450469

13. Neubauer K, Weigel A, Daubmann A et al (2014) Paths to first treatment and duration of untreated illness in anorexia nervosa: are there differences according to age of onset? Eur Eat Disord Rev 22:292-298. https://doi.org/10.1002/erv.2300

14. Ruuska J, Koivisto A-M, Rantanen P, Kaltiala-Heino R (2007) Psychosocial functioning needs attention in adolescent eating disorders. Nord J Psychiatry 61:452-458. https://doi. org/10.1080/08039480701773253

15. Hessler JB, Heuser J, Schlegl S et al (2019) Impact of comorbid borderline personality disorder on inpatient treatment for bulimia nervosa: analysis of routine data. Borderline Personal Disord Emot Dysregul 6:1. https://doi.org/10.1186/s40479-018-0098-4

16. Marucci S, Ragione LD, De Iaco G et al (2018) Anorexia nervosa and comorbid psychopathology. Endocr Metab Immune Disord Drug Targets 18:316-324. https://doi.org/10.2174/18715 30318666180213111637

17. Strober M (2004) Managing the chronic, treatment-resistant patient with anorexia nervosa. Int J Eat Disord 36:245-255. https ://doi.org/10.1002/eat.20054

18. Landi P, Marazziti D, Rutigliano G, Dell'Osso L (2016) Insight in psychiatry and neurology: state of the art, and hypotheses. Harv
Rev Psychiatry 24:214-228. https://doi.org/10.1097/HRP.00000 00000000083

19. Gorwood P, Duriez P, Lengvenyte A et al (2019) Clinical insight in anorexia nervosa: associated and predictive factors. Psychiatry Res 281:112561. https://doi.org/10.1016/j.psychres.2019.112561

20. Bitter I, Fehér L, Tényi T, Czobor P (2015) Treatment adherence and insight in schizophrenia. Psychiatr Hung 30:18-26

21. Belvederi Murri M, Amore M (2019) The multiple dimensions of insight in schizophrenia-spectrum disorders. Schizophr Bull 45:277-283. https://doi.org/10.1093/schbul/sby092

22. Tiller J, Schmidt U, Treasure J (1993) Compulsory treatment for anorexia nervosa: compassion or coercion? The Br J Psychiatry 162:679-680. https://doi.org/10.1192/bjp.162.5.679

23. Túry F, Szalai T, Szumska I (2019) Compulsory treatment in eating disorders: control, provocation, and the coercion paradox. J Clin Psychol 75:1444-1454. https://doi.org/10.1002/jclp.22783

24. Elzakkers IFFM, Danner UN, Hoek HW et al (2014) Compulsory treatment in anorexia nervosa: a review. Int J Eat Disord 47:845-852. https://doi.org/10.1002/eat.22330

25. Thiels C (2008) Forced treatment of patients with anorexia. Curr Opin Psychiatry 21:495-498. https://doi.org/10.1097/YCO.0b013 e328305e45c

26. Yager J, Devlin MJ, Halmi KA et al (2014) Guideline Watch (August 2012): practice guideline for the treatment of patients with eating disorders. 3rd edn. FOCUS 12:416-431. https://doi. org/10.1176/appi.focus.120404

27. Hay P, Chinn D, Forbes D et al (2014) Royal Australian and New Zealand College of Psychiatrists clinical practice guidelines for the treatment of eating disorders. Aust N Z J Psychiatry 48:9771008. https://doi.org/10.1177/0004867414555814

28. Fursland A, Freeman J (2014) Introduction: the 12th annual conference of The Australia \& New Zealand Academy for Eating Disorders. J Eat Disord 2:I1. https://doi. org/10.1186/2050-2974-2-S1-I1

29. Robinson P, Rhys Jones W (2018) MARSIPAN: management of really sick patients with anorexia nervosa. BJPsych Advances 24:20-32. https://doi.org/10.1192/bja.2017.2

30. Holm JS, Brixen K, Andries A et al (2012) Reflections on involuntary treatment in the prevention of fatal anorexia nervosa: a review of five cases. Int J Eat Disord 45:93-100. https://doi.org/10.1002/ eat.20915

31. Clausen L, Larsen JT, Bulik CM, Petersen L (2018) A Danish register-based study on involuntary treatment in anorexia nervosa. Int J Eat Disord 51:1213-1222. https://doi.org/10.1002/eat.22968

32. Russell GF (2001) Involuntary treatment in anorexia nervosa. Psychiatr Clin North Am 24:337-349

33. Carney T, Tait D, Touyz S (2007) Coercion is coercion? Reflections on trends in the use of compulsion in treating anorexia nervosa. Australas Psychiatry 15:390-395. https://doi. org/10.1080/10398560701458202

34. Douzenis A, Michopoulos I (2015) Involuntary admission: the case of anorexia nervosa. Int J Law Psychiatry 39:31-35. https:// doi.org/10.1016/j.ijlp.2015.01.018

35. Milano W, Cotugno A, Grave RD et al (2017) Il trattamento sanitario obbligatorio come salvavita in presenza di disturbi dell'alimentazione: una scelta complessa. Riv Psichiatria 52:180-188

36. Halvorsen I, Tollefsen H, Rø Ø (2016) Rates of weight gain during specialised inpatient treatment for anorexia nervosa. Adv Eat Disord 4:156-166. https://doi.org/10.1080/21662630.2016.11384 13

37. Ward A, Ramsay R, Russell G, Treasure J (2015) Follow-up mortality study of compulsorily treated patients with anorexia nervosa. Int J Eat Disord 48:860-865. https://doi.org/10.1002/ eat. 22377 
38. Clausen L, Jones A (2014) A systematic review of the frequency, duration, type and effect of involuntary treatment for people with anorexia nervosa, and an analysis of patient characteristics. J Eat Disord 2:29. https://doi.org/10.1186/s40337-014-0029-8

39. Moher D, Shamseer L, Clarke M et al (2015) Preferred reporting items for systematic review and meta-analysis protocols (PRISMA-P) 2015 statement. Syst Rev 4:1. https://doi. org/10.1186/2046-4053-4-1

40. Wells GA, Shea B, O'Connell D, Peterson J, Welch V, Losos M, et al (2009) The Newcastle-Ottawa Scale (NOS) for assessing the quality if nonrandomized studies in meta-analyses. http://www. ohri.ca/programs/clinical_epidemiology/oxford.asp. Accessed 9 Mar 2020

41. Ayton A, Keen C, Lask B (2009) Pros and cons of using the Mental Health Act for severe eating disorders in adolescents. Eur Eat Disord Rev J Eat Disord Assoc 17:14-23. https://doi.org/10.1002/ erv. 887

42. Ramsay R, Ward A, Treasure J, Russell GF (1999) Compulsory treatment in anorexia nervosa. Short-term benefits and long-term mortality. Br J Psychiatry 175:147-153. https://doi.org/10.1192/ bjp. 175.2 .147

43. Serfaty M, McCluskey S (1998) Compulsory treatment of anorexia nervosa and the moribund patient. Eur Eat Disord Rev 6:27-37. https://doi.org/10.1002/(SICI)1099-0968(199803)6:1<27:AIDERV192>3.0.CO;2-5

44. Carney T, Crim D, Wakefield A et al (2006) Reflections on coercion in the treatment of severe anorexia nervosa. The Israel J Psychiatry Relat Sci 43:159-165

45. Carney T, Tait D, Richardson A, Touyz S (2008) Why (and when) clinicians compel treatment of anorexia nervosa patients. Eur Eat Disord Rev 16:199-206. https://doi.org/10.1002/erv.845

46. Griffiths RA, Beumont PJ, Russell J et al (1997) The use of guardianship legislation for anorexia nervosa: a report of 15 cases. Aust N Z J Psychiatry 31:525-531. https://doi.org/10.3109/00048 679709065074
47. Watson TL, Bowers WA, Andersen AE (2000) Involuntary treatment of eating disorders. Am J Psychiatry 157:1806-1810. https ://doi.org/10.1176/appi.ajp.157.11.1806

48. Espíndola CR, Blay SL (2013) Long term remission of anorexia nervosa: factors involved in the outcome of female patients. PLoS ONE 8:e56275. https://doi.org/10.1371/journal.pone.0056275

49. Noordenbos G, Seubring A (2006) Criteria for recovery from eating disorders according to patients and therapists. Eat Disord 14:41-54. https://doi.org/10.1080/10640260500296756

50. (2020) Body mass index-BMI. In: World Health Organization. https://www.euro.who.int/en/health-topics/disease-prevention/ nutrition/a-healthy-lifestyle/body-mass-index-bmi. Accessed 2 May 2020

51. Tan JOA, Stewart A, Fitzpatrick R, Hope T (2010) Attitudes of patients with anorexia nervosa to compulsory treatment and coercion. Int J Law Psychiatry 33:13-19. https://doi.org/10.1016/j. ijlp.2009.10.003

52. Rojo L, Barberá M, Plumed J et al (2009) Hospitalization due to eating behavior disorders. Patient and family satisfaction. Actas Esp Psiquiatr 37:267-275

53. Guarda AS, Pinto AM, Coughlin JW et al (2007) Perceived coercion and change in perceived need for admission in patients hospitalized for eating disorders. The Am J Psychiatry 164:108-114

54. Molyneaux E, Turner A, Candy B et al (2019) Crisis-planning interventions for people with psychotic illness or bipolar disorder: systematic review and meta-analyses. BJ Psych Open 5:e53. https ://doi.org/10.1192/bjo.2019.28

Publisher's Note Springer Nature remains neutral with regard to jurisdictional claims in published maps and institutional affiliations. 